\title{
Schema Therapy for Patients with Bipolar Disorder: Theoretical Framework and Application
}

\author{
Marie Ociskova (D) \\ Jan Prasko (D) ${ }^{1-3}$ \\ Krystof Kantor (1D \\ Frantisek Hodny (D) \\ Pavel Kasyanik (iD) ${ }^{4}$ \\ Michaela Holubova ${ }^{5,6}$ \\ Jakub Vanek (ID) \\ Milos Slepecky ${ }^{2}$ \\ Vlastimil Nesnidal (1D) \\ Kamila Minarikova \\ Belohradova (D) \\ 'Department of Psychiatry, University \\ Hospital Olomouc, Faculty of Medicine \\ Palacky University in Olomouc, \\ Olomouc, The Czech Republic; \\ ${ }^{2}$ Department of Psychology Sciences, \\ Faculty of Social Science and Health Care, \\ Constantine the Philosopher University \\ in Nitra, Nitra, The Slovak Republic; \\ ${ }^{3}$ Department of Psychotherapy, Institute \\ for Postgraduate Training in Health Care, \\ Prague, The Czech Republic; ${ }^{4}$ Schema \\ Therapy Institute, St. Petersburg, Russia; \\ ${ }^{5}$ Department of Pedagogy and \\ Psychology, Faculty of Science, \\ Humanities and Education, Technical \\ University of Liberec, Liberec, The Czech \\ Republic; ${ }^{6}$ Department of Psychiatry, \\ Regional Hospital Liberec, Liberec, The \\ Czech Republic
}

Correspondence: Jan Prasko

Email praskojan@seznam.cz

\begin{abstract}
Bipolar disorder (BD) is a severe mood disorder characterized by episodes of depression and hypomania or mania. Despite its primarily biological roots, the onset and course of the disorder have also been related to psychosocial factors such as early adverse experiences and related maladaptive schemas. Several researchers proposed a schema therapeutic model to treat patients with BD. In this paper, we further develop the theoretical model and elaborate on seven elements that were found effective in the psychosocial interventions with individuals with BD: monitoring mood and early symptoms of relapse, recognizing and management of stressful situations and interpersonal conflicts, creating a relapse prevention plan, stabilizing the sleep/ wake cycle and daily routine, encouraging the use of medication, and reducing self-stigma and substance use. Apart from that, we describe the elements of the schema work with patients who suffer from BD. Illustrative clinical cases accompany the theoretical framework. The research of the schema therapy with patients with severe mental illnesses has only recently started developing. The presented paper also aims to encourage further research in this area and highlight potentially beneficial research goals.
\end{abstract}

Keywords: bipolar disorder, schema therapy, early adverse experiences, imagery rescripting, relapse prevention, self-stigma

\section{Introduction}

Bipolar disorder (BD) is a severe mood disorder characterized by episodes of depression and hypomania or mania. ${ }^{1}$ It has a variable course, and its clinical picture can be very heterogeneous, ranging from mild affective episodes to severe phases with psychotic symptoms. ${ }^{1}$ Lifetime prevalence is $0.6 \%$ for bipolar disorder - type I (BD-I), $0.4 \%$ for type II (BD-II), and $1.4 \%$ for subsyndromal bipolar disorder - a total of $2.4 \%$ for bipolar spectrum disorders in the general population. ${ }^{2}$ The disorder occurs approximately equally in men and women and across ethnic and cultural groups. ${ }^{3}$ Heritability is around $57 \%$ for BD-I and $46 \%$ for BD-II. ${ }^{4}$

The treatment of choice is pharmacotherapy. ${ }^{5,6}$ Additional psychosocial interventions may increase compliance with the pharmacotherapy, reduce subsyndromal symptoms and the risk of relapse, and improve the psychosocial functioning and quality of life. $^{7,8}$ The current place of the psychosocial interventions in the treatment of BD analyses the detailed Canadian Network for Mood and Anxiety Treatments (CANMAT) and International Society for Bipolar Disorders (ISBD) guidelines. ${ }^{5}$ Yatham et $\mathrm{al}^{5}$ highlight the usefulness of several adjunctive psychosocial interventions during acute depressive episodes and maintenance treatment, namely cognitive behavioural therapy, family-focused therapy, interpersonal social rhythm therapy, and peer support. These approaches have two main goals - relapse prevention and restoration of 
the quality of life. The guidelines also bring attention to the prevalent stigma and self-stigma as issues that should be tackled in the treatment. ${ }^{5}$ Furthermore, they recommend offering psychoeducation to all patients but mention that it has not brought significant evidence of its utility in the acute phases of the disorder. The psychoeducation should then present a part of every treatment modality, including the psychotherapy, and consist of the following parts: ${ }^{5}$

- Teaching skills in detecting and managing prodromes of depression and mania

- Ongoing stress management and problem-solving

- Creating personalized coping strategies to prevent relapse

- Developing healthy lifestyles (for example, minimizing the use of substances, including caffeine; getting regular exercise; and regulating sleep and wake times)

- Providing tips on enhancing medication adherence

- Diminishing the effects of stigma and denial of the illness

The recently updated guideline of the National Institute for Health and Care Excellency (NICE) for the treatment of BD recommends several evidence-based psychotherapeutic approaches, namely cognitive behavioural therapy, interpersonal therapy, and behavioural couples therapy. ${ }^{6}$ There has not been any psychosocial intervention that has proved effective in treating acute (hypo)manic episodes. ${ }^{5,6}$ Given the disorder's impact on interpersonal relationships, offering a family intervention should be a part of the longer-term management in secondary care. ${ }^{6}$ The NICE guideline then names necessary parts of individual and group psychotherapeutic interventions to prevent relapse. ${ }^{6}$ These largely overlap with the CANMAT and ISBD content of psychoeducation. The NICE guideline stresses tailoring the program to individual's needs based on an individualized assessment and case conceptualization. The authors also recommend providing information about $\mathrm{BD}$, emphasizing general self-monitoring of mood, thoughts, and behaviour, and considering their influence on mood and relapse. ${ }^{6}$

According to Hawke et al, ${ }^{9}$ the schema therapy - a novel approach to treating challenging mental disorders such as borderline personality disorder - may also be beneficial in treating BD. The idea of applying schema therapy to the treatment of $\mathrm{BD}$ has also been expressed by other authors. ${ }^{10,11}$ As a recently established therapeutic approach, it has been gradually forming a basis of research concerning its potential and effectiveness in various disorders. Though modest in numbers, studies focusing on the schema therapy and BD have brought intriguing results. This paper describes the current state of knowledge in the field of the schema therapy of patients with bipolar disorder and further develops a therapeutic model proposed by Hawke et al. ${ }^{9}$ The presented framework is based on the criteria of effective psychosocial interventions. ${ }^{5,6} \mathrm{We}$ also discuss the place of the schema work in the psychotherapy of BD. Case vignettes accompany the theoretical framework. The described patients agreed to have their cases published and signed informed consent. Several demographic and clinical factors were changed to ensure the anonymity of the individuals.

\section{Bipolar Disorder and Early Adverse Experiences}

Patients with BD tend to experience more early adverse experiences than the general population. ${ }^{12}$ In a study by Watson et al, ${ }^{12}$ individuals with BD-I experienced physical and emotional abuse and neglect in childhood more often than controls. Persons with BD who underwent severe childhood maltreatment develop BD at an earlier age (at 15.8 years versus 21.6 years in patients who were not severely abused). ${ }^{13-15}$ They also experience more manic (17.7 versus 7.0) and depressive (30.4 versus 12.0) episodes throughout their lives, and their symptoms tend to be more severe. ${ }^{13,14}$

Early adverse experiences relate to the course and characteristic traits of BD. Rapid cycling has been connected with a history of sexual abuse ${ }^{12,15}$ and physical abuse. ${ }^{15}$ The severity of suicidal symptoms has been linked to a history of physical and sexual abuse ${ }^{15}$ and physical neglect. ${ }^{12}$ Physical and emotional abuse and emotional neglect have been connected with the severity of aggression. ${ }^{15}$ Patients with bipolar disorder who experienced neglect have an increased incidence of melancholic depression. ${ }^{12}$ Childhood abuse also increases the risk of comorbid post-traumatic stress disorder and substance abuse $\mathrm{e}^{12,13,15}$ and comorbid anxiety disorders in this population. ${ }^{13}$

Childhood trauma generally negatively influences affect regulation, impulse control, and cognitive functioning. ${ }^{16}$ It interacts with inherited biological dispositions and alters critical pathways and processes such as the hypothalamic-pituitary-adrenal axis, serotonergic transmissions, neuroplasticity, or circadian rhythms. ${ }^{16}$ Via these pathways, the early adversities may influence the patients well into adulthood. 


\section{Early Maladaptive Schemas and Modes in Bipolar Disorder}

Early maladaptive schemas (EMS) present a potential mediator between early adverse experiences and adult BD. Young et $\mathrm{al}^{17}$ defines the schemas as "broad, pervasive themes or patterns, comprised of memories, emotions, cognitions, and bodily sensations, regarding oneself and one's relationships with others, developed during childhood or adolescence, elaborated throughout one's lifetime and dysfunctional to a significant degree". Like other mental disorders, BD has been associated with a wide range of EMS. ${ }^{18,19}$ Individuals with a higher risk of developing $\mathrm{BD}$, identified by an increased score in the Hypomanic Personality Scale, showed increased severity of most schemas. The most significant schemas of this group were increased Entitlement/Grandiosity and Vulnerability to Harm or Illness and decreased Emotional Inhibition. ${ }^{20}$

In another study by Hawke \& Provencher, ${ }^{18}$ patients with BD differed from patients with unipolar depression in higher Approval-Seeking/Recognition-Seeking and Entitlement schemas even after controlling for current depressive symptoms. Nilsson et $\mathrm{al}^{19}$ then identified seven schemas potentially distinguishing patients with unipolar depression and bipolar disorder, finding more severe schemas in the bipolar group. The current findings suggest that patients with $\mathrm{BD}$ dispose of a wide range of EMS. The results of individual studies are also rather heterogeneous and show little consensus when it comes to identifying the more BD-specific schemas. However, even at this point, some schemas seem to be more common in patients with BD. These are Entitlement, Vulnerability to Harm or Illness, and Approval-Seeking/ Recognition-Seeking (Table 1).

Furthermore, Entitlement/Grandiosity and Defectiveness/ Shame schemas were connected with the severity of suicidal ideation of individuals with $\mathrm{BD} .{ }^{21}$ Individuals with $\mathrm{BD}$ and a lifetime suicidal attempt also scored higher in the Entitlement and Social Isolation/Alienation schemas. ${ }^{21}$

These schemas trigger emotional pain, discomfort, or exhaustion and decrease functioning in various life areas. ${ }^{17} \mathrm{~A}$ person can cope with the schemas in three general ways: ${ }^{17}$

(a) Surrender: Accepting the schema as truthfully reflecting the reality and following it.

(b) Avoidance: Avoiding potential triggers of the schema.

(c) Overcompensation: Acting contrary to the schema.
Table 2 shows examples of coping related to the schemas common in the individuals at risk or with $\mathrm{BD} .{ }^{17}$

Although these three schemas are commonly present in individuals at risk or diagnosed with $\mathrm{BD}$, the patients can also have any other EMS. Schema identification can be challenging. Uncovering the schemas may be easier during affective episodes because the schemas may be well compensated in remission. ${ }^{22}$ Various situations may activate different schemas that would otherwise remain latent. ${ }^{22}$ Depressive and (hypo)manic episodes can differ in activating events and underlying schemas or coping.

Apart from the EMSs, schema therapy recognizes schema modes that present "those schemas or schema operations - adaptive and maladaptive - that are currently active for an individual". ${ }^{17}$ The schemas are "trait-like", while the modes are "state-like". ${ }^{23}$ The modes are ever-changing and differ in their duration and content among individuals. ${ }^{17}$ Ten basic modes form four clusters - child modes, dysfunctional coping modes, dysfunctional parent modes, and the Healthy Adult mode. ${ }^{17}$ The child modes include the Vulnerable Child, the Angry Child, the Impulsive/Undisciplined Child, and the Happy Child. Three coping modes reflect the ways to respond to the maladaptive schema that were already mentioned: avoidance (the Detached Protector), surrender (the Compliant Surrenderer), and overcompensation (the Overcompensator). Two dysfunctional parental modes consist of the Demanding and the Punitive mode (the Critic). The tenth mode is the Healthy Adult, which takes care of the other modes and handles life demands, resembling the psychoanalytic term "ego" ${ }^{17}$ Schema therapy puts increased attention on the mode work through which it influences the maladaptive schemas. However, modes and their change during the treatment of patients with $\mathrm{BD}$ have not been researched yet.

The following case illustrates the connection between schemas and bipolar symptomatology.

Kate first encountered psychiatry as a middle-aged woman during a manic episode. She barely slept and spent most of the time cooking and shopping with money borrowed from her sisters. She was also doing various house chores, even in the middle of the night. She was annoyed that her husband and children looked anxious and suggested that she needed professional help instead of appreciating her. After two weeks of continuous shopping, cleaning, cooking, distributing food to relatives, and inviting neighbours and passers-by to feasts, the exhausted family took her to a psychiatrist. After the initial examination, her husband Simon persuaded Kate to be 
Table I Common Early Maladaptive Schemas in Individuals at Risk or with a Diagnosed Bipolar Disorder

\begin{tabular}{|c|c|c|c|}
\hline $\begin{array}{l}\text { Early } \\
\text { Maladaptive } \\
\text { Schemas }\end{array}$ & Cognitions & Emotions & Somatic Reactions \\
\hline $\begin{array}{l}\text { Entitlement/ } \\
\text { Grandiosity }\end{array}$ & $\begin{array}{l}\text { I am unique and exceptional. I am sure someone will write a } \\
\text { book about me one day. People can consider themselves happy } \\
\text { to know me. It's an honour for them! My needs come first. } \\
\text { Those who criticise me are just envious! I can do anything I } \\
\text { want! }\end{array}$ & $\begin{array}{l}\text { Curiosity } \\
\text { Joyfulness } \\
\text { Contempt } \\
\text { Excitement }\end{array}$ & $\begin{array}{l}\text { Feeling energetic and strong } \\
\text { Energetic movements } \\
\text { Mild agitation } \\
\text { Increased muscle tension } \\
\text { Proud, offended, or stand-offish } \\
\text { facial expressions }\end{array}$ \\
\hline $\begin{array}{l}\text { Vulnerability to } \\
\text { Harm or Illness }\end{array}$ & $\begin{array}{l}\text { I am fragile and vulnerable. The world is dangerous! I am not } \\
\text { safe! I cannot prevent the disaster from happening! I cannot } \\
\text { handle the stress! I am weak! }\end{array}$ & $\begin{array}{l}\text { Anxiety } \\
\quad \text { Fear } \\
\text { Helplessness } \\
\text { Irritability }\end{array}$ & $\begin{array}{l}\text { Increased muscle tension } \\
\text { Chronic fatigue } \\
\text { Frequent headache } \\
\text { Increased physical responsiveness } \\
\text { to medication }\end{array}$ \\
\hline $\begin{array}{l}\text { Approval- } \\
\text { Seeking/ } \\
\text { Recognition- } \\
\text { Seeking }\end{array}$ & $\begin{array}{l}\text { Everyone must like me and pay attention to me. If they do not } \\
\text { notice me or praise me, it means I am worthless and rejected. I } \\
\text { am not worthy of love! My value depends on other people. I } \\
\text { must work hard to be acceptable! }\end{array}$ & $\begin{array}{l}\text { Anxiety } \\
\text { Tense expectations } \\
\text { Sadness and regret } \\
\text { Anger when needs are } \\
\text { not saturated }\end{array}$ & $\begin{array}{l}\text { Increased muscle tension } \\
\text { Restlessness } \\
\text { Exhaustion } \\
\text { Sometimes digestive problems }\end{array}$ \\
\hline
\end{tabular}

Table 2 Examples of Coping in Schemas That are More Common in Individuals at Risk or with a Diagnosed Bipolar Disorder (Young et al 2003)

\begin{tabular}{|l|c|c|c|}
\hline $\begin{array}{l}\text { Early Maladaptive } \\
\text { Schemas }\end{array}$ & Surrender & Avoidance & Overcompensation \\
\hline $\begin{array}{l}\text { Entitlement/ } \\
\text { Grandiosity }\end{array}$ & $\begin{array}{c}\text { Boasting and requiring others to admire } \\
\text { them and to satisfy all their needs. }\end{array}$ & $\begin{array}{c}\text { Avoiding situations in which } \\
\text { they could seem average and } \\
\text { not special. }\end{array}$ & $\begin{array}{c}\text { Taking excellent care of others, being the } \\
\text { most modest and humblest. }\end{array}$ \\
\hline $\begin{array}{l}\text { Vulnerability to } \\
\text { Harm or Illness }\end{array}$ & $\begin{array}{c}\text { Compulsively searching news about various } \\
\text { disasters, pondering possible sources of } \\
\text { danger in daily life. }\end{array}$ & $\begin{array}{c}\text { Avoiding places that they do } \\
\text { not consider safe. }\end{array}$ & $\begin{array}{c}\text { Plunging into danger. Seeking adrenaline } \\
\text { sports and risky situations to prove that } \\
\text { they are invulnerable. }\end{array}$ \\
\hline $\begin{array}{l}\text { Approval-Seeking/ } \\
\text { Recognition- } \\
\text { Seeking }\end{array}$ & $\begin{array}{c}\text { Trying to impress others - mainly by their } \\
\text { actions but also by their status or } \\
\text { appearance. }\end{array}$ & $\begin{array}{c}\text { Avoiding individuals from } \\
\text { whom they desire acceptance } \\
\text { and recognition. }\end{array}$ & $\begin{array}{c}\text { Behaving invisibly, remaining in the } \\
\text { background, or acting as a rebel to be } \\
\text { rejected by others. }\end{array}$ \\
\hline
\end{tabular}

admitted to a psychiatric ward. During the hospitalization, Kate started using lithium. The manic episode remitted, and Kate became ashamed of her behaviour. At that time, the psychiatrist educated Kate about the disorder, the treatment, and what she could do to feel better and reduce the risk of another episode.

A detailed anamnesis revealed that Kate had grown up in a low-income family. Her parents worked hard to support the family, but their salaries were insufficient to provide for seven children. As a result, they were often hungry. Their situation was strenuous because they could not rely on the support of other relatives. They did not have any aunts or uncles, grandparents, or cousins because all of them were killed during the holocaust. The surviving family was displaced in Czechoslovakia and unable to return home to Austria. They were also forced to carefully hide their German accents to avoid further persecution from post-war anti-German sentiments, increasing the tension. Kate's mom had frequent nightmares and was often jumpy and irritable She was constantly afraid of another Shoah. Kate's dad had bouts of severe depression. Kate remembered how she had grown up in an atmosphere of fear and despair accompanied by hunger. The family mostly ate plain bread that had to be locked in a pantry 
so that the children would not eat all of it. Kate and her siblings were often crying from hunger until they fell asleep. Although the parents were heartbroken when they saw their children suffer, they could not afford more food. Still, the family later managed to move to another region that offered better job opportunities. As they finally got enough food, the tension at home decreased. However, Kate remembered the memories of the hunger and the tense atmosphere at home.

As a young adult, Kate married Simon, a man who had promised her heaven and Earth. She was in love and believed that they would have a good life. They had two children - a son and a daughter - who were soon recognized as gifted in mathematics and music. The parents were proud of them, but their relationship had gradually worsened. Simon never praised Kate. He was also highly orderly and demanded a spotless household. She was prone to anxiety and often sought reassuring, which irritated Simon and the children alike. The children were quite restless and noisy, which fuelled the tension at home and led to frequent quarrels.

In the retrospective, Kate was not immediately aware of the trigger of her manic episode. She enjoyed the experience while it lasted. She felt vital, creative, and full of strength which was a welcomed change from her usual anxiety and self-doubts. She later realized that the episode's trigger might have been a moment when she found that her husband spent his whole salary in the pub and was unfaithful to her with a waitress. The finding initially shattered Kate, but she quickly stopped being sad and anxious during the episode. After the manic phase subsided, Kate became ashamed of her behaviour and was afraid of what her relatives and neighbours would say about her actions. Simon also felt ashamed of her but was determined to encourage Kate to take medication. The children were happy "to have their mom back".

Two early maladaptive schemas were particularly active and shaped the manic episode:

1. Vulnerability to Harm or Illness - Kate coped with this schema by avoidance. She was trying to prevent the risk of hunger by excessively cooking and feeding herself, her family, neighbours, and passers-by. Outside of the episode, Kate had always made sure that there was enough food at home. During mania, this tendency became excessive. The schema had two primary childhood sources - the experienced hunger and the prevalent anxiety of Kate's mother. Simon's excessive spending was one of the triggers of the episode.

\section{Approval Seeking and Recognition Seeking - Kate} surrendered to this schema. She has been seeking acceptance and praise through diligent work for her whole life. Outside of the manic episode, Kate subtly showed others her work results to get praised or accepted. She longed to be accepted by everyone. During the manic episode, these tendencies also intensified. She baked a cake at 1 AM, vacuumed the whole apartment at $2 \mathrm{AM}$, or cleaned the windows at $4 \mathrm{AM}$. She was not tired but was rather excited and proudly presented the results of her work to gain praise. The schema was based on her childhood experiences of being one of many siblings wanting to secure parents' attention and watching for triggers of mother's anxiety and father's depression to get along. Kate's finding of Simon's infidelity likely contributed to the onset of mania, and the excessive house chores and cooking also served as an attempt to regain his acceptance.

These two schemas were also manifesting outside the mania, but they became much more pronounced during the episode. After remitting, Kate was ashamed of her behaviour. Her outpatient psychiatrist repeatedly asked both her husband and children to come to a joint session, but they wanted to avoid the stigma attached to psychiatry and refused. They also thought that their attendance in the therapeutic sessions would confirm that Kate had a mental disorder which they considered unacceptable Kate subsequently repeatedly discontinued her medication because it reminded her that she was "crazy". As a result, she had more episodes of mania, after which followed a first depressive episode. The depression manifested after Simon left Kate because of another woman and applied for a divorce. Kate felt broken and hopeless. Both of her parents recently died, and her children were gradually leaving the family nest. Her siblings pressured her to start using the medication again, but Kate saw it as pointless. She did everything she could to make things work, to keep the family intact, and it was not enough. Considering suicide, Kate sought her psychiatrist. During the therapeutic interview, it became clear that the following schemas dominated the depressive episode:

1. Negativity/Pessimism - This schema was usually latent but got triggered by Simon's file for divorce. Kate was increasingly helpless and prone to noticing only negative aspects of her life and thought that she would never be able to start another relationship. She stopped trying to improve her situation. She surrendered to the schema and sometimes drank alcohol to push away the pain for a while (schema avoidance). This worked only short term and 
brought long-term issues. The schema had roots in childhood when she often felt hopeless about her family's and her prospects. Kate also might have developed it by social learning from her dad when he was depressed.

2. Defectiveness/Shame - Kate surrendered to this schema, believing that she was worse than others. For example, Kate did not complete high school because she believed she was not good enough to finish it. The schema intensified after Simon left her. Kate felt worthless. In the long-term perspective, the schema has also been reflected in her attitude towards the psychotropic medication that reminded her that she was "crazy" and thus inferior. The schema had roots in the poor living conditions during her childhood when she perceived herself as worse than other children.

3. Failure to Achieve - Her divorce triggered this schema, and Kate surrendered to it. Kate believed that she had failed as a wife and a mother. She gave up trying to care for her children and herself and stayed in a bed for days. The schema was mainly associated with her experience of dropping out of school during her adolescence due to her lack of self-confidence. Because her family had always placed a great emphasis on education, she perceived it as a significant failure.

When comparing the EMSs during the manic and depressive episodes, several points stand out:

(a) The early maladaptive schemas were intensely active in both phases. Some schemas were active both in and outside the episodes; others were latent and only appeared during the phases. This does not mean that the schemas are "responsible" for BD. However, stronger EMS may increase the vulnerability to the development of BD and its relapse. ${ }^{20}$ The schemas also shape the specific manifestation of the disorder.

(b) In the presented case, the episodes of opposite polarity were connected with different schemas. It is not a rule - The patient may experience the same schemas in mania and depression, only through different coping. The active schema likely depends on a triggering situation. For example, a young man with BD recently split up with his fiancée. This triggered his Defectiveness/Shame schema ("I'm so worthless that I can't even keep a family together."). When they settled on the break-up, he became depressed. He sought supportive therapy but refused mood stabilizers because he feared the label of having BD. The pair lived alongside for a while, and then he moved to another flat and officially left the family. We expected that he would become depressed again, but he got hypomanic instead. He was excessively spending money and bought many presents and valuable assets for his little daughter that remained with her mother. $\mathrm{He}$ became persuaded that he was perfect and externalized the guilt for the break-up solely to his exfiancée. Thus, the same schema led to two different manifestations of $\mathrm{BD}$.

(c) Both phases usually differ in the prevalent coping with the schemas. The response to a schema heavily depends on the available sources of energy. At the same time, the response may block the energy by itself; for example, surrendering "saves" energy that may be used at different times. During mania, a patient can generally devote extreme amounts of energy to coping. An individual with the Vulnerability to Harm or Illness schema may overcompensate by seeking danger and behaving recklessly, and they can devote vast amounts of time, money, and energy to it while being manic. In the depressive phase, patients have diminished access to their energy and may be prone to more energyconserving coping. Taking the example of the Vulnerability to Harm or Illness, such individual may increasingly avoid potentially dangerous situations (even if they are not threatening) and deprive themselves of potentially pleasurable activities. This may maintain their depression and increase the risk of another episode. ${ }^{24}$ A patient, who is depressed and has a Defectiveness/Shame schema, may socially isolate themselves because they fear being recognized as worthless. The same patient can overcompensate and become condescending to others, boastful, and irradiate the aura of a perfect human being while being manic.

Kate was repeatedly hospitalized in a psychiatric hospital for both manic and depressive episodes. Her condition fluctuated for several years, with relapses occurring approximately once a year, usually after Kate discontinued the medication. She discontinued it mainly because of the side effects. Kate also thought that taking psychiatric drugs meant that she was "insane", which was very painful. Her medication was also a sad reminder of her former husband, who told her condescendingly on several occasions that 
she was "crazy". Repeated discontinuation of the drugs in combination with conflicts with the ex-husband led to relapses. Only after many years she was also offered psychotherapy.

\section{Basic Steps of Schema Therapy in Bipolar Disorder}

The general course of the schema therapy, which includes an initial assessment, education, bypassing maladaptive coping modes, taking care of the Vulnerable Child, or stopping the Critical mode, is modified to suit the needs of the patients with BD. ${ }^{9}$ We enriched the steps proposed by Hawke et $\mathrm{al}^{9}$ with psychotherapeutic and psychoeducational elements that are generally effective in BD. ${ }^{5,6}$ The schema therapy should start with an individualized assessment and schema therapeutic case conceptualization. The therapist also needs to provide understandable and acceptable information about the disorder. ${ }^{6}$ The core of the therapeutic relationship lies in the limited reparenting. ${ }^{17}$ Sessions may be individual, group, or couple/family. Family support is essential in all stages of the treatment, but the active participation of the relatives in the treatment needs to follow the patient's informed decision. A family intervention may be beneficial during the longer-term management. ${ }^{6}$ The following part describes general parts of the schema therapy adjusted to the needs of the patients with bipolar disorder.

\section{Monitoring Mood and Early Symptoms of Relapse}

Monitoring mood and symptoms of relapse are one of the core strategies in patients with affective disorder. Monitoring develops self-reflection, which present a part of the Healthy Adult. It can be applied retrospectively (when examining circumstances of the onset of recent relapse) or on the present situation (daily monitoring in a diary). ${ }^{25}$ Consistent and longer-term monitoring helps to automatize awareness of the mood and its triggers. ${ }^{25}$ Mood monitoring charts and worksheets take on many forms and can be individualized according to a specific patient's needs, motivation, and current phase of the therapy. If a patient's mood significantly fluctuates during the day (the mood is worse in the morning or the evening), they can evaluate their mood several times a day. ${ }^{25}$

Schema therapists may enhance mood monitoring by parallel modes monitoring, consisting of thoughts, emotions, bodily sensations, and behaviour. The patient might also benefit from monitoring their unmet emotional needs and related early memories. The worksheets should be simple and easy to complete in all cases, especially when working with currently symptomatic or less motivated individuals. For example, the patient might pick a smiley from a defined set to describe their mood and focus only on the most influential modes: the coping modes, the Critic, and the Vulnerable Child. Lengthy writing should be avoided as it can decrease motivation to keep monitoring in many patients who struggle with attention.

Apart from the mood and modes monitoring, a patient and a therapist identify early signs of relapse based on previous episodes. These signs can warn about an upcoming relapse, and an adequate reaction can prevent it from developing. ${ }^{25}$ It is helpful to write two lists - one for depressive symptoms, the other for (hypo)mania.

\section{Recognising and Management of Stressful Situations and Interpersonal Conflicts}

Reinforcing stress management skills is essential in the therapy of BD., ${ }^{5,6,26}$ Sources of stress usually relate to work (unemployment, struggles at school), relationships (quarrels, loneliness), daily functioning (financial and time management), and physical condition (comorbid physical illnesses, adverse effects of medication). Schema therapy pays increased attention to issues that:

- repeatedly occur,

- link to patients' early aversive experiences, and

- result at least partly from the patient's schemas. ${ }^{17}$

The schema therapeutic work starts with monitoring the modes and unmet needs. The therapist and the patient then use the affective bridge (described lower) to identify a childhood memory related to these repeating experiences. They perform the imagery rescripting of the early memory to meet the identified needs (usually by securing safety or acceptance). Apart from the relief, the imagery rescripting brings up new ways of coping and self-support. As the patient imagines meeting their past needs, they gradually internalize more effective reactions to stressful or frustrating events. The rescripting often brings a powerful message that the patient may apply in the present (for example, "It is ok to ask for help."). After the rescripting, the therapist and the patient return to the current stressor and apply the adaptive message to it. The patient may then experiment with the new approach in their daily life. Apart 
from using the imagery rescripting, strengthening the stress management skills includes applying cognitive strategies (for example, more balanced beliefs related to a problem) and behavioural strategies (a training of communication skills and problem-solving skills as direct empowerment of the Healthy Adult).

The motivation to work on stressful situations is affected by a level of insight. ${ }^{7}$ Some patients think that they do not have any problems. When others express concerns, they believe that others envy them their ideas and good mood. This is especially common in hypomania. When such a patient visits a therapist, it is mainly because their relatives forced them to do it, not because the individual wants it. Identification of the sources of stress and their management may prove difficult in such cases. The first step is to use the guided discovery. The therapist avoids putting the patient under even more pressure and instead connects with their Healthy Adult. The guided discovery presents a discussion between two Healthy Adults (the therapist's and the patient's). The therapist may ask whether the patient is aware of any difference from their average experience or self-perception. Through curious and open-ended questions, the therapist helps the patient become aware of the differences in his everyday experience, using the self-reflective abilities of the Healthy Adult. After building positive rapport, they may use the two-column technique that further empowers the Healthy Adult. In this technique, the therapist and the patient consider the evidence for the absence and the presence of a specific issue (Table 3).

One of the most common psychosocial stressors that precede bipolar episodes are interpersonal conflicts. ${ }^{27}$ Role-playing situations focusing on coping with criticism, underestimation, rejection, and acquiring assertive skills can help the patients increase their resilience to the psychosocial struggles and reduce the stress load that may trigger a future episode. ${ }^{28}$ It is necessary to describe the challenging communication situations in detail, write down the communication sequences, and gradually practice alternative interactions. ${ }^{29}$ Discussing and playing the modes of both parties can make the social skills training fun and attractive to the patients. A significant part of the training is also taking the stance of the communicating partner, not only playing themselves. The patient may gain valuable insights and find a well-suited response in a difficult situation that would otherwise not be come up.

\section{Creating a Relapse Prevention Plan}

The plan can take on forms. The NICE guideline ${ }^{6}$ suggests creating the plan in collaboration with the patient and their carer and sharing it with the patient, their carer, and general

Table 3 Example of the Two-Column Technique

\begin{tabular}{|l|l|}
\hline \multicolumn{2}{|l|}{ Problem: I have a good and practical idea to buy a yurt, but my wife disagrees. } \\
\hline My idea to buy a yurt is practical. & My idea to buy a yurt is a little hasty. \\
\hline $\begin{array}{l}\text { Living in a yurt is healthier than living in a flat. } \\
\text { We have only a tiny shack in our garden. It is so little that we cannot } \\
\text { sleep in it. It would be nice to be able to stay there overnight. }\end{array}$ & $\begin{array}{l}\text { I do not know if living in a yurt is actually healthier. } \\
\text { The garden is quite close to our home. It is half an hour on foot. Living in } \\
\text { the yurt would be more complicated than simply returning to our home. } \\
\text { We'd save just a little money on gasoline. Heating the yurt would cost a lot. }\end{array}$ \\
$\begin{array}{l}\text { The yurt is heated and warm throughout the year. } \\
\text { It would be romantic to stay there, and it would improve our } \\
\text { relationship. }\end{array}$ & $\begin{array}{l}\text { There is nothing to do in the garden in the winter. We probably would not } \\
\text { stay there. } \\
\text { I can invite friends there. We could spend time together, and all of us a cheaper way to be romantic; we can start by going on short } \\
\text { could sleep there. }\end{array}$ \\
$\begin{array}{l}\text { If we fight at home, one of us could go to the yurt before we'd calm } \\
\text { down. }\end{array}$ & $\begin{array}{l}\text { I do not like the garden very much. } \\
\text { We do not have friends that we could invite to spend the night in the yurt. } \\
\text { I do not know if my wife would like to spend time in the yurt. Probably not, } \\
\text { and I would rather stay at home too. } \\
\text { The yurt is quite expensive. } \\
\text { Neither my wife nor children want a yurt; we'd probably fight about it. } \\
\text { If we built a yurt in the garden, there would not be much room for the } \\
\text { flower beds; the garden is not that big. }\end{array}$ \\
\hline Conclusion: I liked the idea very much, but it is not the right time
\end{tabular}


practitioner. This risk management plan should consist of the following parts: ${ }^{6}$

- Identifiable personal, social, occupational, or environmental triggers and early warning signs of relapse (mentioned above)

- A protocol for applying an individual's coping strategies and medication management

- Agreements between primary and secondary care about ways of responding to an increased risk or a concern about a possible risk

- Information about whom to contact if the patient or their carer is concerned or in a crisis, including the names and contacts of healthcare workers in primary and secondary care

We have been using a personalized form of the NICE guideline. Such a plan consists of monitoring the early warning signs and the steps to take if they occur:

(1) My typical triggers and early symptoms of depression and (hypo)mania

(2) My relapse prevention steps

(a) What will I do to prevent the full development of a (hypo)manic/depressive episode?

(b) What will I ask my relatives and loved ones to do for me?

(c) What will I ask my relatives and loved ones to tell me?

(d) What will I ask from my psychiatrist and therapist?

The last point also includes the contact information of the healthcare professionals and close facilities. Sometimes, the patient is dissatisfied with their normal mood, missing "the beauty and colours of hypomania". The memories of mania and depression usually bring sorrow and worries. However, pleasant memories of feeling a bit more confident than usual, becoming a social butterfly, having many creative ideas, and experiencing everything as more colourful and enjoyable can be craved. The longing patients often forget the troubles that the hypomanic episode brought. The wish to feel "alive" and "superb" needs to be legitimized as understandable - Who does not like feeling great? Then, a joint discussion about hypomania's pros and cons reinforces the Healthy Adult (Table 4).

After the cognitive work on the advantages and disadvantages, developing the Happy Child in everyday activities is advisable. This can be done by guided imagery of pleasant activities, planning more enjoyable activities into everyday life, and realizing this plan with a subsequent reappraisal of the whole process. These activities can include quality time with family and friends, sport, and relaxing activities. Focusing on joyful activities helps to decrease the temptation of hypomania.

\section{Stabilizing the Circadian Rhythms and Daily Routine}

Stabilizing the circadian rhythms is an essential step in gaining and maintaining remission. This step lies at the core of interpersonal and social rhythm therapy, the evidence-based treatment of $\mathrm{BD}^{30}$ It is built around the assumption that a regular regime (consisting of sleep, eating, exercise, and social interactions) and a reduction in interpersonal stress leads to stable circadian rhythmicity. ${ }^{27}$ The regular circadian rhythms decrease the overstimulation that usually precedes relapse. ${ }^{27}$ It provides safety and predictability to the patient's life. Because maintaining a stable regime is easier said than done, the therapeutic work requires a careful analysis of instability triggers and their management. This is usually done by working with maladaptive coping modes (leading to

Table 4 Advantages and Disadvantages of Hypomania

\begin{tabular}{|c|c|}
\hline Advantages & Disadvantages \\
\hline $\begin{array}{l}\square \text { Life is generally more colourful, faster, and adventurous. } \\
\square \text { I am more interested in sex which makes my partner happy as } \\
\text { well. } \\
\square \text { I have many ideas. } \\
\square \text { I am more confident and comfortable while communicating with } \\
\text { people, talking to the authorities, and arranging things. (...) }\end{array}$ & $\begin{array}{l}\square \text { I am fiercer, and I often get into conflicts at home, at work, and even in the } \\
\text { store - whenever someone does not comply or disagrees with me. } \\
\square \text { I was lost a job in hypomania once because I carelessly said what I thought } \\
\text { of my boss. } \\
\square \text { I tend to be too honest; I am less tactful, often quite arrogant. } \\
\square \text { I finish few things because I quickly get attracted to other ideas. (...) }\end{array}$ \\
\hline
\end{tabular}

Conclusion of the Kind Parent and the Healthy Adult: I understand why l'd like to experience hypomania again, but I also know that it would not be wise. It would bring more harm than good. However, I can plan more pleasurable activities and enjoy my Happy Child this way. 
overworking or avoidance), taking care of unmet emotional needs, and reinforcing Healthy Adult skills (time planning, problem-solving, communication skills). The work on the circadian rhythms takes place throughout many sessions; slips are common and understandable. They present learning opportunities, highlighting potential blind spots that need to be addressed. Maintaining stable rhythms is not the goal; maintaining good enough rhythms are.

\section{Encouraging the Use of Medication}

Insufficient cooperation in medication use (either an irregular use or withdrawal) occurs in up to $50 \%$ of patients with BD. ${ }^{31}$ There are two common approaches to increasing adherence: psychoeducation and motivational interview. $^{32}$

The psychoeducation first aims to understand how the patient perceives the disorder and the medication, including its potential side effects. The patients often hold stereotypes and myths ("Drugs change your personality.", "Taking long-term medication means you're crazy.", "Pills take away your freedom.") and need more realistic information. Other times, the patients forget to take their medication. The second part of the psychoeducation works with the patient's specific beliefs, concerns, and experiences to achieve better treatment adherence. ${ }^{25}$

The motivational interview generally serves to increase the likelihood of a change towards more positive behaviour and includes the following steps: ${ }^{33,34}$

(1) Discussing of patient's beliefs associated with the medication

(2) Mapping the advantages and disadvantages of using and not using medication with a four-field table

(3) Creating a plan to deal with the potential obstacles to using medication and its adverse reactions, would they occur

(4) Securing patient's active involvement in developing and participating in the treatment plan

While this step may be more aimed at psychiatrists providing the pharmacotherapy, the psychotherapist also needs to focus on treatment adherence. The reasons are that pharmacological therapy is the treatment of choice in $\mathrm{BD}$ and low adherence to the medication significantly influences psychotherapy as well.

\section{Reducing Self-Stigma}

The self-stigma presents a significant issue that requires our therapeutic attention. ${ }^{5}$ It negatively influences the quality of life of the individuals with $\mathrm{BD}$ and their medication adherence and cooperation in psychotherapy in patients with $\mathrm{BD} .^{5,35,36}$ The general approach of handling the self-stigma consists of enhancing adaptive coping skills through improvements in self-esteem, empowerment, and help-seeking behaviour. ${ }^{5}$ There are more ways to meet this goal. The first step to reducing self-stigma consists of psychoeducation about $\mathrm{BD}$ and its treatment. Psychoeducation increases positive attitudes towards oneself and the treatment and decreases the risk of relapse. ${ }^{26}$ It is helpful to inform the patient that BD does not mean any inferiority or weakness as they often think. On the contrary, many influential and creative people had it as well (Johann Wolfgang von Goethe, Winston Churchill, Ernest Hemingway, Virginia Wolf, and others).

The next step is to attribute self-stigmatizing ideas to the Critic ("You're worthless! Everyone will reject you! You can't be helped!") and search for their sources in the past. It is then possible to conduct a mode dialogue with the modes that play a part in the self-stigmatization. These are usually the Critic, the Vulnerable Child ("I feel rejected and unloved."), the Detached Protector ("I should end it all."), and the Surrenderer ('It's pointless. I can't be helped. I'll stop using the meds.”). The patient speaks about their self-stigmatization from the perspective of each mode and then addresses them with their Healthy Adult. The therapist and the patient may switch roles during the talking to the modes to find fitting responses and so that the patient may experience relief when they are recipients and only listen to the therapist talking to the modes.

The patient may also need to prepare for potential real stigmatization and discrimination by others. ${ }^{37}$ This means to be prepared for possible insensitive remarks, criticism, rejection, or work and housing discrimination. The training aims to learn to communicate in these situations assertively, from the Healthy Adult position, without the passive submission of the Surrenderer or the sharp criticism of others in the Angry Child's mode. It is recommended to work on these situations if they arise, not in advance, as their prospects could frighten the patient. They might become afraid that they will be discriminated against or rejected when they may not even experience such behaviour. The therapeutic work focused on the identity related to the mental disorder ("Me as a person with BD”) may be helpful in any case.

\section{Reducing Substance Use}

Excessive substance use presents a significant issue for many patients with $\mathrm{BD} .{ }^{38}$ Abuse of alcohol and other 
substances worsens adherence in pharmacotherapy and psychotherapy and increases the likelihood of manic episodes. ${ }^{39}$ Depressive episodes become longer and more severe. ${ }^{38,40}$ From the point of schema therapy, alcohol abuse is connected with Detached Protector and Surrenderer. A patient with BD and substance use disorder often has stormy relationships; their conflicts and risky behaviour becomes more common. The therapist can identify the substance use through typical conversation with the patient, specific questions, spontaneous reports from the patient's relatives, or direct observation of an intoxicated patient in the session. It is essential to show understanding with the patient's effort to protect themselves from stress. The excessive use of alcohol and other substance presents a sensitive topic. Apart from the continuous limited reparenting, the therapist may benefit from motivational interviews and support the patient from seeking abstinence or at least controlled drinking (in the case of alcohol). The therapist and the patient may complete the four-field table showing the advantages and disadvantages of substance use. The patient can often continue the outpatient therapy, but a more severe addiction requires hospitalization in a dedicated department. Still, few studies show the apparent effectiveness of this approach in patients with $\mathrm{BD}$ and comorbid substance use disorder. ${ }^{41}$ One more extensive study found good outcomes in psychosocial approaches in this group. ${ }^{42}$

\section{Schema Work}

Although the schema work has not been described as one of the basic steps of effective psychotherapy of individuals with $\mathrm{BD}$, we added this part in the schema therapeutic model as well. The reason for this decision is that many early maladaptive schemas are more common in patients with BD than in controls. ${ }^{19,20,43-45}$ While there has not been established a direct link between the schemas and the development or a course of $\mathrm{BD}$, the treatment of the schemas may bring relief to the patients and potentially improve the prognosis of the disorder. ${ }^{9}$ The basics of the schema work in patients with bipolar disorder does not significantly differ from the general approach used in other disorders. ${ }^{17}$ We have had a good experience with the following therapeutic techniques:

\section{Cognitive Work}

The early maladaptive schemas can be identified in different ways. They manifest in the therapeutic relationship (transference and counter-transference), in the repeating topics that come up in daily life, specific techniques such as the mode dialogue, or schema-therapeutic questionnaires. No matter how the schemas have been identified, the patient may benefit from writing down important information concerning the schema. It creates order out of chaos and helps the patient to perceive the schema as understandable and manageable. This may be especially important for patients with mood disorders who often perceive their symptoms as uncontrollable and threatening. The worksheet can take many forms according to the patient's needs; an example is in Table 5. The patient completes the sheet with the therapist gradually. Basic facts related to the schema may be written down early in the therapy, followed by experiential work targeted at the schema (here, imagery rescripting). As known from the cognitive therapy, ${ }^{46}$ the cognitive work is usually applied when the patient sufficiently processed their schema on the emotional level, and their Healthy Adult got more robust.

\section{Experiential Work}

In addition to their cognitive component, the schemas also have an emotional component that is better addressed by limited reparenting and experiential techniques. ${ }^{17}$ The experiential work does not significantly differ from the established approach.

\section{The Affective Bridge Based on Imagery or Role- Playing}

The affective bridge technique connects a present situation with a past event through an emotional similarity of both events. ${ }^{47}$ The connection is identified by a reason or outward similarities but by a shared emotional core, such as a mixture of deep sadness and disappointment. There are four steps of the affective bridge:

(1) Activation of the image: The therapist asks the patient to access the emotion/s related to a current or a described event.

(2) The predominant emotion is then used as a bridge to the related childhood event. Once the patient imagines the early memory, the therapist helps him to keep focusing on the image.

(3) Subsequently, they perform the imagery rescripting of the early memory. The rescripting can be performed directly in imagery or indirectly through transference objects such as toys or chairs.

(4) The newly established positive emotions and insights then transfer back to the current situation, and their application leads to new approaches and potential 
Table 5 Example of Schema Work

Schema: Defectiveness/Shame (Related core belief: I am useless.)

Schema analysis

- Origin (How did I learn it?)

- Maintenance (Which events and which behaviour maintain the schema?)

- Functioning (How does the schema manifest in relationships, work, leisure time?)

- Advantages and disadvantages (What are the advantages and disadvantages of the schema?
My father was physically disabled, and he criticised me for making mistakes in my

homework and kept telling me that I was stupid and good for nothing. He used to compare me with my classmates and named things in which they were better. On one occasion, he said that he would rather have Peter as a son than me because Peter was a junior judo star, and everyone liked him. My mother frequently criticised me and never praised me. Lada bullied me in kindergarten and kept saying that I had to serve him. My grandma used to tell me that I was clumsy and that I better not touch anything to break it.

I was putting much effort to get good marks at school to prevent triggering the schema. I often offered help with easy tasks at home and at school to get at least some praise, but I avoided difficult tasks so that no one would see how inept I really was. Usually, I still avoid doing difficult tasks and accept many easy tasks at work. I help with some tasks at home but avoid those that seem more challenging.

I was afraid to start dating for a long time because I did not believe any girl would want me. I am dependent on my wife, and if she does not praise me, I feel miserable and think I am useless. I have been trying very hard to make everyone see how good I have been during my whole career. I do not have much free time because I cannot keep up with the duties I willingly take on.

It makes me demoralised when I am depressed and unable to do anything. On the contrary, I do too many things in mania - so many that I cannot finish them. That annoys others who rely on me; they criticise me and do not trust me, making me feel useless. On the other side, the overcompensation led me to achieve things that I am proud of - I became an associate professor soon, have done valuable research in my field, and raised several talented researchers. I also wrote a praised textbook that is recommended all over the country.

A scathing criticism by my father when I got a B on a math exam. I felt stupid and incompetent. *** My grandfather came in and stood up for me. He scolded my dad and praised me. He then helped me with calculating some examples and realised that I understood them well.

When I was around five, I wanted to help pulling water from our pond in the garden; I fell into it and started drowning. I was terrified. My father pulled me out, beat me up, and scolded me for it. *** I imagined myself as an adult entering and criticised my father for not paying attention to me and letting me recklessly pull the water from the pond. Then I took little Tommy from his arms and told him that he was smart, that he did it well, that he accidentally slipped, which happens to everyone, and that it turned out well. I added that it was nice for him to want to help and help with the housework. Then we played with a helicopter toy.

As a child and a teenager, I constructed various toy models of cars, tractors, harvesters, and later motorbikes. I did it very well, and my grandpa praised me for them. Even my dad appreciated them. I had mainly As at the school, and I managed my university studies without significant problems. I have been successful at work and got promoted early. I created a new unit that works very well. I give lectures to students, and I am good at doing it because they tell me that I am the best lecturer and that they like attending my lectures. It's probably true because the capacity of my lectures is almost always full.

I am pretty witty and smart; I often have good and original ideas.

I believe it at $80 \%$.

\section{A new attitude towards myself}

- How would a more accurate look at yourself look like?

- How much do I trust it? 
Table 5 (Continued).

\begin{tabular}{|l|l|}
\hline $\begin{array}{l}\text { A bright dream about my life with the new } \\
\text { attitude: }\end{array}$ & $\begin{array}{l}\text { I'd be more confident in my everyday life and would not try to show everyone how } \\
\text { well I do things but rather enjoy doing them. I would not come up with new projects at } \\
\text { and lived according to it? }\end{array}$ \\
$\begin{array}{ll}\text { - What do I need to learn to make it happen? } \\
\text { work often, but I would finish those already in progress first. Maybe I would talk more } \\
\text { about my needs with my wife and not always show her how much I can do. Instead of } \\
\text { assembling new machines in the garden all the time, I would help her more at home } \\
\text { (though she also wants to show how perfect she is, it's not just me). } \\
\text { I need to learn not to jump from one activity to another, finish one task first, and start } \\
\text { another. I need to learn time planning to stay up late at night not to become } \\
\text { overworked. l'd also like to plan more enjoyable activities with my wife and children. } \\
\text { I can go to the high school ball with my wife and daughter. Our daughter is great at } \\
\text { dancing, she will enjoy it very much and we will too. }\end{array}$
\end{tabular}

solutions. The discovered solutions may be then put into practice.

According to our clinical experience, patients with bipolar disorder usually accept this technique well. They are often imaginative and connect with their emotions relatively quickly, especially when mildly symptomatic or in remission. While the patients often have a rational understanding that the relapses are usually triggered by psychosocial stress and that early adverse events may increase the sensitivity towards the mood disorder, the affective bridge helps them to experience that it is indeed so and that it is their lived experience that influences how they feel. It also provides them with an insight that differs from the usual intellectual one.

\section{Imagery Rescripting of Aversive Childhood Experiences}

Therapist: When we discussed how your schemas of Defectiveness/Shame and Unrelenting Standards developed, you said that your father often criticized you. $\mathrm{He}$ criticized you for the school grades, which was paradoxical because you were actually learning very well. Do you remember any situation when it happened?

Thomas: Hmm, hmm, that happened on many occasions, practically every time I got a B in a test ...

Therapist: It must have been difficult for you when your father considered only the good marks ... Do you remember one specific situation when it happened? ... Which one enters your mind first?

Thomas: Yeah, one was particularly bad. I was in the fifth grade. You know, I've always been good at math, but I made a mistake while writing down a result then. It was a crucial semi-annual test, and I got a B. My father was raging. He said he didn't understand how his son could have done something like that. He himself always excelled at math. He said he was ashamed of a son who wasn't smart enough to finish the fifth grade, although I finished it, just with a B on a semi-annual test. I felt terrible, like a total loser. It felt as if he punched me into the ground.

Therapist: It must have been very humiliating. I'm sorry that you had to experience something like that ... Could you try to think about what you needed the most at that moment? Like a child who's good at math but made one mistake. That can happen to anyone ... I think you said that you always had As in math in your annual school reports.

Thomas: That's right; math has always been easy for me. I've also represented my school in math competitions. However, at that moment, I believed I was stupid, though it seemed a little unfair. My dad was furious ... What did I need? I guess someone to stand up for me. Someone who wouldn't allow my father to humiliate me and would instead set him limits ...

Therapist: You say it so decisively ... It's good that you realize the needs of little Tommy. Do you have an idea who could protect him? It could be either someone you know, someone from your past or your current life. It could also be you as an adult man ...

Thomas: I think I'd feel the best if my grandpa came in. Dad respected him. Grandpa was once a rich miller, a confident and diligent man. He also liked me a lot because he saw himself in me. My dad had a grudge against him. Grandpa used to be against dad's marriage with his daughter because my dad was poor and was from a wealthy family ...

Therapist: I'm sorry to hear that those two struggled with each other, but I like the idea of the grandpa coming in. He sounds like someone who liked you very much and could stand up to you. Let us go back to what grandpa should do to help you. You said you'd need someone to stand up to your dad. What should it look like? 
Thomas: He could just say: "Michael, don't talk to my grandson like that and don't say that you're ashamed of him! If you can't control yourself, go outside and chop some wood. You can vent on it however you like. However, don't talk like that to my grandson. Do you understand?!"

Therapist: Grandpa is resolute, that's right ... Now, if you'd like, try to close your eyes and imagine the whole scene as a movie ...

Thomas: Dad shouts at me that he doesn't understand how he could have such a stupid son and that he's ashamed of me ... Grandpa enters, and dad is startled and stops immediately. Grandpa says coldly: "Michael, you won't treat my grandson like that. Do you understand?! He's a clever boy, and you are hurting him. Look at him, how bad he feels! If you can't control yourself, go outside and chop some wood. You can scream there as you like, but never put down my grandson! Do you understand?!” Dad looks ashamed and leaves ...

Therapist: And how do you feel, Tommy?

Thomas: Pretty well, I feel that grandpa is behind me, and I feel stronger. However, I'm still a little shaken by my dad's yelling.

Therapist: What else would you need?

Thomas: I still need my grandpa to reassure me ...

Therapist: Imagine what he should say or do.

Thomas: Grandpa hugs me and holds me for a while. He says I'm smart; one B doesn't mean anything. That I just made a mistake; he knew I was great at math and a great child. He's proud of me. However, if I want to feel reassured, we could solve a math task together. He believes that it will be a piece of cake for me. Then we go to my room. I solve a complicated math task with ease. Grandpa says: "So you see, you're doing great; you can trust yourself."

\section{Therapeutic Letters}

Therapeutic letters present a set of valuable techniques that help to relieve the pressure of self-criticism or excessive worries (the Critic) and reinforce dignified and loving selfacceptance (the Healthy Adult). Importantly, patients do not send the letters to the addressed person because these are intended for emotional processing, not for passing blame and heating conflicts. The use of therapeutic letters needs to be planned concerning the patient's current state.
A patient in hypomania may write a colourful and vivid uncensored letter and impulsively send it to the close person (often a parent). They might consider it a great idea at that time but later usually feel regret and face unnecessary conflicts. Such sensitive techniques would then be better suited for remission when the patient is more stable.

Prasko et $\mathrm{al}^{48}$ described four therapeutic letters:

1. The Uncensored Letter: The patient writes to a person most closely related to the Critic development. It may be a parent, a grandparent, a sibling, a teacher, or a classmate who either hurt, punished, or embarrassed the patient in their childhood or continuously failed to fulfil the patient's core emotional needs. The letter is uncensored, which means that the patient may write down everything they need. The predominant points of view are those of the Vulnerable and Angry Child, but they may be accompanied by the Healthy Adult or the Critic directed at the person. The patient reads the letter to an empty chair or some other object, imagining the person sitting on it during a session.

2. The Letter from the Other Side: The ideal letter the patient would have wanted to receive from the person "receiving" the Uncensored Letter. If the patient cannot imagine that the person would behave kindly or admit their mistakes and apologize, she can imagine another appropriate figure writing the letter. This letter does not aim at mending the relationship with the specific person but to reinforce the patient's Healthy Adult. This is why the patient can change the imagined individuals writing the second letter. The letter may contain words of encouragement, acceptance, appreciation, beliefs about the patient's abilities, or apologies the options are vast. The therapist reads this letter to the patient so that the patient can immerse into the healing emotions. This creates a cathartic experience.

3. The Kind Letter to the Critic as a Child: This letter to the persons from the first and (usually) second letters when they were children. The patient writes from the Healthy Adult perspective. They accept and empower the person when they were a child. The patient needs to know beforehand what the person was experiencing during their childhood, what problems they had, what they liked doing, 
and who cared about them. This letter helps the patient gain another perspective on their critical or abusive behaviour and reinforce their own Healthy Adult mode. They realize that the person was also once a child with unmet needs, empathize with their suffering, and feel sympathetic towards them. This further absolves them from their inner Critic.

It is essential to consider the timing of this letter carefully. It would best come after the patient's own emotional needs have been sufficiently met - both in the present and in the past. A premature assignment may trigger hurt (the Vulnerable Child: "I'm lonely. No-one cares about me. It's all about making others feel good, I'm invisible."), detachment (the Detached Protector: "I don't know what to write to him. I don't care about his childhood issues."), criticism (the Critic: "She went through a lot, so she should've known better and not be such a lousy parent!"), anger (the Angry Child: "F*ck you and your damn excuses! You sucked, and I hate you!"), and other modes other than the Healthy Adult. However, a timely assignment can significantly progress the therapeutic work and reinforce the Healthy Adult.

1. The Business Card: This letter is written from the Healthy Adult mode of the patient to the other person from the previous letters. It is written directly, courageously, without manipulative phrases, remorse, or criticism. The letter is intended for reconciliation and dignity, so it takes place as the last one. The patient needs to have a good awareness of their modes to not slip into the Detached Protector. This would lead to a reserved, formal letter instead of "one Healthy Adult to the other Healthy Adult" communication. This assignment helps to boost the Health Adult and increase the autonomy of the patient.

\section{Some Specifics of the Therapeutic Work with Patients Who are Stabilized}

The therapy with a stabilized patient contains all the described steps. It focuses on relapse prevention strategies (monitoring warning signs, stabilizing daily rhythms), schema work, and treatment adherence. Practising social skills might be valuable as well. Supporting treatment adherence is essential because some remitted patients discontinue the medication for various reasons, increasing the risk of relapse. ${ }^{49,50}$

\section{Some Specifics of the Therapeutic Work with Patients Who are Depressed}

In terms of schema therapy, it is essential to start working with the predominant coping mode, often the Surrenderer, then treating the Vulnerable Child and stopping the Critic. It is advisable to use a time planning technique, a classical behavioural strategy that enhances the Healthy Adult. Emotional validation and empathic encouragement to perform manageable tasks and reward them afterwards are particularly important during the therapeutic work with the coping modes and the Critic.

\section{Some Specifics of the Therapeutic Work with Patients Who are Hypomanic}

Working with a patient in hypomania is challenging because the patient is keen, quick, and usually offended by minor remarks and notions. The first step is to help the patient realize that they are experiencing a hypomanic episode, and although we understand that it is enjoyable, they need to take an active approach to it. This can be supported by the Two-Column technique (Table 6). The therapist and the patient discuss the facts that indicate that the mood is natural and that the patient experiences hypomania. If they have established a solid therapeutic relationship and the patient trusts the therapist, this technique may help them decide to take active steps to get the hypomanic episode under control.

\section{Conclusion}

Bipolar disorder is a severe mental disorder that manifests by episodes of depression, hypomania, or mania. ${ }^{1}$ Although it has significant biological correlates and predictors, ${ }^{4,51}$ patients may also benefit from psychotherapy, especially if it incorporates elements of psychoeducation., 5 Previous research has shown that adjunctive psychosocial interventions may positively influence the mental state of the patients with BD and their quality of life and functioning. ${ }^{7,8}$ The psychotherapeutic process should include strategies to increase the awareness and coping with stressors and psychosocial triggers of mood changes, creating a relapse prevention plan, working with a daily regime, increasing adherence to pharmacotherapy, and decreasing substance use and the selfstigma. ${ }^{5,6}$ These steps may be easily incorporated into the schema therapy and enriched with the schema work. Still, the utility of providing the schema therapy to individuals with $\mathrm{BD}$ is yet to be thoroughly explored. 
Table 6 Example of Increasing Insight with the Two-Column Technique

\begin{tabular}{|c|c|}
\hline Facts suggesting that it is just a good mood. & Facts suggesting that it is a hypomanic episode. \\
\hline $\begin{array}{l}\text { - Several people have told me that I am in a good mood. } \\
\text { - I enjoy small things. } \\
\text { - I often laugh. } \\
\text { - I have a lot of good ideas that make me happy. } \\
\text { - I have not done anything embarrassing as I did in mania: I have not danced on the } \\
\text { table in a pub, I have not scolded the cops, I have not given people my money, I have } \\
\text { not hit on every woman I have met (I can control myself although l'd like to). } \\
\text { I do not argue at work, and even if someone tells me something critical, I smile and } \\
\text { forget it right away. }\end{array}$ & $\begin{array}{l}\text { - Indeed, I usually do not have such a good mood. Most of the time, I feel neutral. } \\
\text { - I talk to strangers in the stores, at the bus stop, I address people on the town square } \\
\text { and tell them about the sights, although they show no indication that they would like } \\
\text { to know something about them. They are still happy, but I do not usually do it. } \\
\text { - I look a lot at women on the street; I feel more attracted to them. I usually notice } \\
\text { them only a little, often not at all. } \\
\text { - I have a greater appetite for sex, and my wife is already bothered by that. } \\
\text { - I often go shopping in the store and spend more than usual. } \\
\text { - I do not care what anyone tells me. Usually, I care a lot about what someone says } \\
\text { about me. I am cheeky to the boss and his secretary. }\end{array}$ \\
\hline
\end{tabular}

Research on the schema therapy in individuals with BD is in its infancy which is also a limitation of the presented paper. To date, one paper proposed a general model of the schema-therapeutic work. ${ }^{9}$ Several cross-sectional studies on early maladaptive schemas in BD brought mixed results, ${ }^{18,20,21}$ and no study has explored the modes in this patient group. Future studies need to focus on larger and well-defined samples that would consider the influence of the participants' phase. Various phases of the disorder shape how the schemas present, ${ }^{22}$ which likely contributes to the increased heterogeneity of the results. Apart from these cross-sectional designs, outcome and other interventional studies with sufficient follow-ups are needed. We hope to encourage future research in this promising field.

\section{Ethical Statement}

The ethical committee of the Faculty of Medicine and Dentistry, Palacky University Olomouc, approved the article. All patients signed an informed consent to publish their cases.

\section{Disclosure}

The authors report no conflicts of interest in this work.

\section{References}

1. Spitzer RL, Md KK, Williams JB. Diagnostic and Statistical Manual of Mental Disorders. 5th ed. Arlington, VA: American Psychiatric Association; 2013.

2. Merikangas KR, Jin R, He J, et al. Prevalence and correlates of bipolar spectrum disorder in the World Mental Health Survey Initiative. Arch Gen Psychiatry. 2011;68(3):241-251. doi:10.1001/archgenpsychiatry.2011.12

3. Ferrari AJ, Stockings E, Khoo JP, et al. The prevalence and burden of bipolar disorder: findings from the Global Burden of Disease Study 2013. Bipolar Disord. 2016;18(5):440-450. doi:10.1111/bdi.12423
4. Song J, Kuja-Halkola R, Sjölander A, et al. Specificity in etiology of subtypes of bipolar disorder: evidence from a Swedish populationbased family study. Biol Psychiatry. 2018;84(11):810-816. doi:10.1016/j.biopsych.2017.11.014

5. Yatham LN, Kennedy SH, Parikh SV, et al. Canadian Network for Mood and Anxiety Treatments (CANMAT) and International Society for Bipolar Disorders (ISBD) 2018 guidelines for the management of patients with bipolar disorder. Bipolar Disord. 2018;20(2):97-170. doi:10.1111/bdi.12609

6. National Collaborating Centre for Mental Health (UK). Bipolar Disorder: The NICE Guideline on the Assessment and Management of Bipolar Disorder in Adults, Children and Young People in Primary and Secondary Care. London: The British Psychological Society and The Royal College of Psychiatrists; 2014.

7. Schwartz HA, Swanson J. Psychotherapy for bipolar disorder in adults: a review of evidence. Focus (Am Psychiatr Publ). 2014;12 (3):251-266. doi:10.1176/appi.focus.12.3.251

8. Goodwin GM, Haddad PM, Ferrier IN, et al. Evidence-based guidelines for treating bipolar disorder: revised third edition recommendations from the British Association for Psychopharmacology. $J$ Psychopharmacol. 2016;30(6):495-553. doi:10.1177/0269881116 636545

9. Hawke LD, Provencher MD, Parikh SV. Schema therapy for bipolar disorder: a conceptual model and future directions. J Affect Dis. 2013;148(1):118-122. doi:10.1016/j.jad.2012.10.034

10. Ball J, Mitchell P, Malhi G, Skillecorn A, Smith M. Schema-focused cognitive therapy for bipolar disorder: reducing vulnerability to relapse through attitudinal change. Aust $N$ Z J Psychiatry. 2003;37 (1):41-48. doi:10.1046/j.1440-1614.2003.01098.x

11. Munuera C, Weil F, Minois I, et al. L'exploration des Schémas Précoces Inadaptés (SPI) chez les personnes adultes atteintes de troubles bipolaires: une revue systématique de la littérature scientifique [Exploring early maladaptative schemas (EMS) in adults with bipolar disorder: a systematic review of the scientific literature]. Encephale. 2020;46(1):65-77. French. doi:10.1016/j. encep.2019.09.005

12. Watson S, Gallagher P, Dougall D, et al. Childhood trauma in bipolar disorder. Aust NZ J Psychiatr. 2014;48(6):564-570. doi:10.1177/ 0004867413516681

13. Agnew-Blais J, Danese A. Childhood maltreatment and unfavourable clinical outcomes in bipolar disorder: a systematic review and metaanalysis. Lancet Psychiatr. 2016;3(4):342-349. doi:10.1016/S22150366(15)00544-1

14. Garno JL, Goldberg JF, Ramirez PM, Ritzler BA. Impact of childhood abuse on the clinical course of bipolar disorder. Br J Psychiatry. 2005;186:121-125. doi:10.1192/bjp.186.2.121 
15. Daruy-Filho L, Brietzke E, Lafer B, Grassi-Oliveira R. Childhood maltreatment and clinical outcomes of bipolar disorder. Acta Psychiatr Scand. 2011;124(6):427-434. doi:10.1111/j.16000447.2011.01756.x

16. Aas M, Henry C, Andreassen OA, Bellivier F, Melle I, Etain B. The role of childhood trauma in bipolar disorders. Int $J$ Bipolar Disord. 2016;4:2. doi:10.1186/s40345-015-0042-0

17. Young JE, Klosko JS, Weishaar ME. Schema Therapy: A Practitioner's Guide. New York: The Guilford Press; 2003.

18. Hawke LD, Provencher MD. Early maladaptive schemas among patients diagnosed with bipolar disorder. J Affect Dis. 2012;136 (3):803-811. doi:10.1016/j.jad.2011.09.036

19. Nilsson KK, Nielsen Straarup K, Halvorsen M. Early maladaptive schemas: a comparison between bipolar disorder and major depressive disorder. Clin Psychol Psychother. 2015;22(5):387-391. doi: $10.1002 / \mathrm{cpp} .1896$

20. Hawke LD, Provencher MD, Arntz A. Early maladaptive schemas in the risk for bipolar spectrum disorders. J Affect Dis. 2011;133 (3):428-436. doi:10.1016/j.jad.2011.04.040

21. Khosravani V, Mohammadzadeh A, Bastan FS, Amirinezhad A, Amini M. Early maladaptive schemas and suicidal risk in inpatients with bipolar disorder. Psychiatry Res. 2019;271:351-359. doi:10.1016/j.psychres.2018.11.067

22. Beck AT, Haigh EAP. Advances in cognitive theory and therapy: the generic cognitive model. Annu Rev Clin Psychol. 2014;10:1-24. doi:10.1146/annurev-clinpsy-032813-153734

23. Lobbestael J, van Vreeswijk M, Arntz A. Shedding light on schema modes: a clarification of the mode concept and its current research status. Neth J Psychol. 2007;63(3):76-85.

24. Veale D. Behavioural activation for depression. Adv Psychiatr Treat. 2008;14:29-36. doi:10.1192/apt.bp.107.004051

25. Lauder SD, Berk M, Castle DJ, Dodd S, Berk L. The role of psychotherapy in bipolar disorder. MJA. 2010;193(4):S31-S35. doi:10.5694/j.1326-5377.2010.tb03895.x

26. Miklowitz DJ, Goodwin GM, Bauer MS, Geddes JR. Common and specific elements of psychosocial treatments for bipolar disorder: a survey of clinicians participating in randomized trials. J Psychiatr Pract. 2008;14(2):77-85. doi:10.1097/01.pra.0000314314.94791.c9

27. Steardo L, Luciano M, Sampogna G, et al. Efficacy of the interpersonal and social rhythm therapy (IPSRT) in patients with bipolar disorder: results from a real-world, controlled trial. Ann Gen Psychiatry. 2020;19:15. doi:10.1186/s12991-020-00266-7

28. Bartels SJ, Pratt SI, Mueser KT, et al. Long-term outcomes of a randomized trial of integrated skills training and preventive healthcare for older adults with serious mental illness. Am J Geriatr Psychiatry. 2014;22(11):1251-1261. doi:10.1016/j.jagp.2013.04.013

29. Vyskocilova J, Prasko J. Social skills training in psychiatry. Act Nerv Super Rediviva. 2012;54(4):159-170.

30. Frank E, Swartz HA, Boland E. Interpersonal and social rhythm therapy: an intervention addressing rhythm dysregulation in bipolar disorder. Dialogues Clin Neurosci. 2007;9(3):325-332.

31. Jawad I, Watson S, Haddad PM, Talbot PS, McAllister-Williams RH. Medication nonadherence in bipolar disorder: a narrative review. Ther Adv Psychopharmacol. 2018;8(12):349-363. doi:10.1177/ 2045125318804364

32. Pakpour AH, Modabbernia A, Lin CY, Saffari M, Ahmadzad Asl M, Webb TL. Promoting medication adherence among patients with bipolar disorder: a multicenter randomized controlled trial of a multifaceted intervention. Psychol Med. 2017;47(14):2528-2539. doi:10.1017/S003329171700109X

33. Miller WR, Conforti K, Rollnick S. Motivational Interviewing: Preparing People for Change. 2nd ed. New York, NY: The Guilford Press; 2002.
34. Patterson TL, Mausbach BT, McKibbin C, Goldman S, Bucardo J, Jeste DV. Functional adaptation skills training (FAST): a randomized trial of a psychosocial intervention for middle-aged and older patients with chronic psychotic disorders. Schizophr Res. 2006;86(1-3):291299. doi:10.1016/j.schres.2006.05.017

35. Latalova K, Ociskova M, Prasko J, Kamaradova D, Jelenova D, Sedlackova Z. Self-stigmatization in patients with bipolar disorder. Neuro Endocrinol Lett. 2013;34(4):265-272.

36. Pascual-Sanchez A, Jenaro C, Montes JM. Understanding social withdrawal in euthymic bipolar patients: the role of stigma. Psychiatry Res. 2020;284:112753. doi:10.1016/j.psychres.2020.112753

37. Brohan E, Gauci D, Sartorius N, Thornicroft G; GAMIAN-Europe Study Group. Self-stigma, empowerment and perceived discrimination among people with bipolar disorder or depression in 13 European countries: the GAMIAN-Europe study. J Affect Disord. 2011;129(1-3):56-63. doi:10.1016/j.jad.2010.09.001

38. Simhandl C, Radua J, König B, Amann BL. Prevalence and impact of comorbid alcohol use disorder in bipolar disorder: a prospective follow-up study. Aust NZ J Psychiatr. 2016;50(4):345-351. doi: $10.1177 / 0004867415585855$

39. Ostacher MJ, Perlis RH, Nierenberg AA, et al. Impact of substance use disorders on recovery from episodes of depression in bipolar disorder patients: prospective data from the Systematic Treatment Enhancement Program for Bipolar Disorder (STEP-BD). Am J Psychiatry. 2010;167 (3):289-297. doi:10.1176/appi.ajp.2009.09020299

40. Pary R, Patel M, Lippmann S. Depression and bipolar disorders in patients with alcohol use disorders. Fed Pract. 2017;34(Supp12):37S-41S.

41. Salloum IM, Brown ES. Management of comorbid bipolar disorder and substance use disorders. Am J Drug Alcohol Abuse. 2017;43 (4):366-376. doi:10.1080/00952990.2017.1292279

42. Gold AK, Peters AT, Otto MW, et al. The impact of substance use disorders on recovery from bipolar depression: results from the Systematic Treatment Enhancement Program for Bipolar Disorder psychosocial treatment trial. Aust NZ J Psychiatr. 2018;52(9):847855. doi:10.1177/0004867418788172

43. Ak M, Lapsekili N, Haciomeroglu B, Sutcigil L, Turkcapar H. Early maladaptive schemas in bipolar disorder. Psychol Psychother. 2012;85(3):260-267. doi:10.1111/j.2044-8341.2011.02037.x

44. Nilsson KK. Early maladaptive schemas and functional impairment in remitted bipolar disorder patients. J Behav Ther Exp Psychiatry. 2012;43(4):1104-1108. doi:10.1016/j.jbtep.2012.05.005

45. Özdin S, Sarisoy G, Sahin AR, et al. Early maladaptive schemas in patients with bipolar and unipolar disorder. Int J Psychiatry Clin Pract. 2018;22(2):151-156. doi:10.1080/13651501.2017.1387268

46. Padesky CA. Schema change processes in cognitive therapy. Clin Psychol Psychother. 1994;1(5):267-278. doi:10.1002/cpp.5640010502

47. Farrell JM, Reiss N, Shaw IA. The Schema Therapy Clinician's Guide: A Complete Resource for Building and Delivering Individual, Group and Integrated Schema Mode Treatment Programs. Hoboken, NJ: John Wiley \& Sons, Ltd; 2014.

48. Prasko J, Diveky T, Mozny P, Sigmundova Z. Therapeutic letters changing the emotional schemas using writing letters to significant caregivers. Act Nerv Super Rediviva. 2009;51(3-4):163-167.

49. Consoloni JL, M'Bailara K, Perchec C, et al. Trajectories of medication adherence in patients with Bipolar Disorder along 2 years-follow-up. $J$ Affect Dis. 2021;282:812-819. doi:10.1016/j.jad.2020.12.192

50. Öhlund L, Ott M, Oja S, et al. Reasons for lithium discontinuation in men and women with bipolar disorder: a retrospective cohort study. BMC Psychiatr. 2018;18:37. doi:10.1186/s12888-018-1622-1

51. Sigitova E, Fišar Z, Hroudová J, Cikánková T, Raboch J. Biological hypotheses and biomarkers of bipolar disorder. Psychiatry Clin Neurosci. 2017;71(2):77-103. doi:10.1111/pen.12476 


\section{Publish your work in this journal}

Neuropsychiatric Disease and Treatment is an international, peerreviewed journal of clinical therapeutics and pharmacology focusing on concise rapid reporting of clinical or pre-clinical studies on a range of neuropsychiatric and neurological disorders. This journal is indexed on PubMed Central, the 'PsycINFO' database and CAS, and is the official journal of The International Neuropsychiatric Association (INA). The manuscript management system is completely online and includes a very quick and fair peer-review system, which is all easy to use. Visit http://www.dovepress.com/testimonials.php to read real quotes from published authors. 